\title{
I Left Vertebral Artery with a Proximal Stenotic Origin and
}

\section{Clinical Implications}

\section{Olutayo Ariyo}

Department of Anatomy Pathology and Cell Biology, SKMC at Thomas Jefferson University, Philadelphia, USA

Corresponding Author: Olutayo Ariyo, Department of Anatomy Pathology and Cell Biology, SKMC at Thomas Jefferson University, Philadelphia, USA

Received: December 10, 2020; Accepted: February 08, 2021; Published: February 16, 2021

Citation: Olutayo Ariyo (2021) I Left Vertebral Artery with a Proximal Stenotic Origin and Clinical Implications. J. Clinical Cardiology and Cardiovascular Interventions, 4(4); Doi:10.31579/2641-0419/119

Copyright: (C) 2021 Olutayo Ariyo, This is an open-access article distributed under the terms of the Creative Commons Attribution License, which permits unrestricted use, distribution, and reproduction in any medium, provided the original author and source are credited.

\begin{abstract}
Even though most vertebral artery anomalies are asymptomatic, but the normally arising vertebral artery from the superoposterior surface of its ipsilateral subclavian artery, plays a vital role, via the Subclavian Steal Syndrome to help in vascularization of its ipsilateral upper limb anatomical structures. The case of a left vertebral artery with a proximal origin stenosis in the left limb of a 72 year -old female cadaver is reported and its pathophysiological consequences of the stenosis in an hypothesized proximal occlusion in ipsilateral subclavian artery considered.

The left vertebral artery originated normally from the superior -posterior surface of the left subclavian artery, but with a proximal stenotic origin in its proximal $1-1 / 2 \mathrm{~mm}$ length.

The LVA was of a good caliber size distal to the stenotic segment, proceeding in its pre-foraminal segment superiorly, entering normally the 6th transverse cervical foraminal to begin its osseous path.

Proximal stenosis of the vertebral artery are uncommon, but this tends to have a deleterious effect on the posterior circulation in the brain depending on the severity of such stenosis. Stenosis although most frequent in the artery's 1st part tends to have more deleterious effect with

Knowledge of vertebral artery pathologies, its variant origins, lumen size, are important to Head and Neck, Neurosurgeons, Interventional Neuroradiologists in the choice of appropriate surgical and medical managements and to neuroradiologists in the interpretation of images.

Keywords: stenotic vertebral proximal origin; proximal subclavian artery stenosis; retrograde flow in vertebral artery; posterior cerebral ischemic stroke; subclavian steal syndrome. (sss).
\end{abstract}

\section{Introduction}

The usual origin of the vertebral arteries are from the superior-posterior surfaces of their ipsilateral subclavian artery, the artery coursing superiorly medial-ward, usually to enter the transverse foramen of the $6^{\text {th }}$ cervical vertebrae. The vertebral artery (VA) is typically divided into 4 segments V1 (preforaminal): origin to transverse foramen of C6, V2 (foraminal): from the transverse foramen of $\mathrm{C}$ VI to the transverse foramen of C2, V3 (atlantic, extradural or extraspinal): from $\mathrm{C} 2$ to the dura and V4 (intradural or intracranial): from the dura to their confluence to form the basilar artery. The $2 \mathrm{VA}$ join to form a single midline basilar artery in the hind brain. Variabilities in the origins and morphology in the VA had been widely reported in surgical, radiologic, poste-mortem and cadaveric studies. Most common variant of the VA is that of aortic arch origin of the LVA originating between the LCCA and the left SA Woraputtaporn W et al (2019), reported an incidence of 5.8\% incidence of the left vertebral artery (LVA) arising between the left common carotid artery (LCCA) and the left subclavian artery (LSA) [ 1 ].Gluncic V et. al, (1999) described the case of an unusual origin of both vertebral arteries in a singular cadaver. On the left, the artery arose directly from the common trunk of vertebral and subclavian artery at the aortic arch and enters the transverse cervical foramina at C VI. The right vertebral artery
(RVA) on the other hand originated from the right common carotid artery (RCCA) and enters the transverse foramina at C III [2].

Stenosis in the vertebral artery can arise in all the different parts of the artery, either proximally, or in the $4^{\text {th }}$ part, just proximal to the formation of the basilar artery.

Vertebral artery origin (VAO) stenosis is occasionally observed in patients who have acute ischemic stroke. It has been reported that the annual event rate for ischemic stroke in the posterior circulation was significantly higher in patients who had asymptomatic VAO $(1.88 \%$ VS $0 \%, \mathrm{p}=0.046)$. VAO stenosis is said to require more clinical attention as a potential source of recurrent stroke when VAO stenosis is observed in patients who have concurrent ischemic stroke in the posterior circulation [3]

Of all cases, vertebral arteries that arose from the aortic arch were much more likely to not only have a more medial course (especially their preforaminal segment) over the cervical vertebral bodies but also to enter a transverse foramen that was more cranially located than the normal C6.

\section{Case Report}


During routine academic dissection in our facility, we observed the left vertebral artery arising normally from the supero-posterior surface of its subclavian artery (the LSA), but with a proximal stenotic origin in its proximal $1-1 / 2 \mathrm{~cm}$ length, The artery was of a good caliber size distal to the stenotic segment proceeding in its pre-foraminal segment superiorly, entering normally at the $6^{\text {th }}$ transverse foraminal to begin its osseous $2^{\text {nd }}$ (V2) segment cranially. We did not observe any aneurysmal dilatation in the artery throughout its preforaminal segment (V1). Inclining medially from its origin, the artery enters normally at the $6^{\text {th }}$ transverse cervical foramen as in the norm.

The right vertebral artery was explored and was also arising found as a variant, not arising from the right subclavian artery, but from the right thyrocervical trunk. No stenosis nor aneurysmal dilation was observed in the preforaminal segment, but the RVA entered higher at the $5^{\text {th }}$ transverse cervical foramina to begin its osseous (V2) segment. The brachiocephalic artery and the LCCA arose independently without a bicaroticus morphology.

\section{Discussion}

The blood supply to the brain is shared between the 2 internal carotid arteries, constituting the anterior circulation (AC) and the vertebrobasilar system supplying the posterior circulation (PC). Circulations between the 2 systems is via the Circle of Willis, the linkage between AC and PC via the 2 posterior cerebral communicating arteries.

Pathologies of the vertebral artery include its many variant origins, tortuosity, atheromatous plaques causing obstruction and narrowing of the vessel. VAO is part of the occlusive disease in the VA, contributing to the occurrence of posterior circulation diseases (PCD). Other causes include atherosclerosis in the basilar artery. Stenosis in the VA may occur either extracranially or intracranial portion of the VA, contributing to annual rate of ischemic stroke of the brain in the occipital fossa.

Pathological studies had been performed on extracranial and intracranial vertebral-basilar

to the vertebral artery include localization of atheroma at the vertebral artery, mid vertebral, C3, the highest percentage at the VAO (Fisher CM (1965) and Schwartz CJ, (1961) [ 4, 5 ]. The most occlusions in the VBS occur at the VAO, or at the site of the stenosis (Hass, 1968) [6]. Castaigeine 1973 [7] and that subsequent to smaller sizes of the VA, plagues produce more stenosis in the vertebral (VA) than in the carotids Schwartz 1961 [5], Fisher 1965 [4]. . These plaques are less ulcerated than in the carotids. As far as the prevalence of stenosis in the VA, RVA Koch et al (2014) reported 5,61\% the prevalence of RVA stenosis as compared to $6.1 \%$ in the LVA. [9]. Hass reported that distal V3 lesions are more symptomatic than proximal V1 stenosis. [6] While occlusion of 1 VA does not assume adequate circulation to the VBC.

A racial and gender distributions had been reported between extracranial and intracranial occlusive lesions, with Asian, Black and women having more predominant intracranial occlusive disease, whereas white men have more extracranial (VAO) lesions.

Management of VAO stenosis is vital to the adequacy of total perfusion of total blood supply to the brain, as pathologies in AC and PC may yield hemorrhagic or ischemic blood flow. Severity of stenosis in the VA especially in the $\mathrm{V} 3$ section contributes more to yearly posterior circulation disease (PCD). Stenosis when very severe may lead to flow deficits.
Quantitative Magnetic Resonance Angiography (QMRA) helps in measurement of specific blood flow in extra and intracranial vessels. QMRA has also been used successfully in the selection of patients who may benefit from medical, interventional or surgical treatment for PCD, based on flow determination with a high success rate, With use of QMRA, , those with normal flows had a much higher stroke free survival than those with low PC flows, (Charbel et al) 2011 [9].

Surgical options in management of pathologies in the VAO, mid and distal vertebral arteries had been reported with use of a variety of bypasses to circumvent stenosis or occlusion in the vertebral or basilar arteries A 90-100\% success rate with use of surgery in patients who had failed medical therapy in patients with extracranial vertebral artery disease had produced complete resolutions of symptoms. Diaz 1984, Hopkins 1987 [10, 11].

A vital role for the normally arising VA is its importance in instances of an occlusion to the proximal subclavian artery. A retrograde flow in the ipsilateral VA will help in delivering blood to the subclavian artery distal to its occlusion thereby helping in the vascularization of the ipsilateral upper limb anatomical structures. A severe stenosis will possibly make the retrograde flow not reaching the subclavian artery, hence a redundant SSS.

Should such an occlusion occur in the proximal SA with a VAO stenotic origin, the severity in of such stenosis will help in determining if such a retrograde flow would aid in vascularization from the importance of the Subclavian Steal Syndrome,

Knowledge of the variant origins and pathological morphologies in the VA are important to cardiothoracic, vascular, Neuro surgeons and Interventional neuroradiologists in the selection of appropriate surgical interventions and to radiologists in the interpretation of images. A-nonimaging of the vertebral artery in aortic arch or subclavian arteriography should not be mistaken as absence of the artery, rather this may be as a result of its very severe stenotic proximal origin and of significance in the selection of appropriate surgical intervention

\section{Conflict of Interest: None.}

\section{Acknowledgement:}

Dedicated to my Great Mentor, Late Professor Adesegun Banjo BSC, MBBS (Oxon) Ph.D (PENN.).

\section{References}

1. Woraputtaporn W, Ananteerrakul T, IaamsardS, Namkin M. Incidence of vertebral artery of aortic arch origin, its level of entry into transverse foramen, length, diameter and clinical significance Anatomical Science International (2019) volume 94, pages 275-279(2019)

2. Gluncic V ,Iykic G, Marin D, et al. Anomalous origin of both vertebral arteries. Clin Anat. 1999;12(4):281-284.

3. Kim, YJ Lee JH,Choi JW, Roh HG, Chun YI, Lee JS, Kim HY BMC Neurology 201313--171 10.1186/1471-2377-13-171.

4. Fisher CM, Gore I, Okabe N, White PD. Atherosclerosis of the Carotid and Vertebral Arteries-Extracranial and Intracranial. J Neuropathol Exp Neurol. 1965. 24: 455-476

5. Schwartz CJ, Mitchell JRA. Atheroma of the Carotid and Vertebral Arterial Systems. BMJ. 1961. 2: 1057-1063 ) 
6. Hass WK. Joint study of extracranial arterial occlusion. II. Arteriography, techniques, sites, and complications. JAMA. 1968. 203: $961-368$

7. Castaigne P, Lhermitte F, Gautier JC, Escourolle R, DerouesnÉ C, Agopian PD, et al. Arterial Occlusions in the Vertebrobasilar System. Brain. 1973;96:133-154

8. Charbel FT, Alaraj A, Amin-Hanjani S. Youmans Neurological Surgery. Elsevier BV; 2011. Extracranial Vertebral Artery Diseases;:2011 pp. 3665-3680.

9. Koch S, Bustillo AJ, Campo B, Campo N, Campo-Bustillo I, McCKartsnelson MS, Kartsnelson M, Romano JG. Prevalence of vertebral artery origin stenosis and occlusion in outpatient extracranial ultrasonography.. J.Vas Interv. Neurology. 20147 (2), 29-33

10. Diaz FG, Ausman JI, de los Reyes RA, Pearce J, Shrontz C, Pak H. Surgical reconstruction of the proximal vertebral artery. J Neurosurg. 1984. 61: 874-881

11. Hopkins LN, Martin NA, Hadley MN, Spetzler RF, Budny J, Carter LP. Vertebrobasilar insufficiency. J Neurosurg. 1987. 66: $662-674(8) 74$ Commons Attribution 4.0 License

\section{To Submit Your Article Click Here: Submit Manuscript}

DOI:10.31579/2641-0419/119
Ready to submit your research? Choose Auctores and benefit from:

* fast, convenient online submission

* rigorous peer review by experienced research in your field

* rapid publication on acceptance

* authors retain copyrights

* unique DOI for all articles

* immediate, unrestricted online access

At Auctores, research is always in progress.

Learn more www.auctoresonline.org/journals/clinical-cardiology-andcardiovascular-interventions 